\title{
Euroraum-Budgethilfenpolitik im rechtlichen Neuland
}

\author{
Peter-Christian Müller-Graff*
}

Die Euroraum-Budgethilfenpolitik stellt seit Mai 2010 die Festigkeit des europäischen Zusammenhalts auf den Prüfstand. Sie bewegt nicht nur die Fragen der politischen und wirtschaftlichen Integrationsfähigkeit und Integrationsbereitschaft der Mitgliedstaaten des Euroraums (Eurostaaten) sowie der passfähigen Ausgestaltung des Demokratieprinzips in der europäischen Integration in ungekannter Intensität. Sie fordert zugleich die Grundfesten des rechtlichen Integrationsacquis und führt in rechtliches Neuland. Es sind mittlerweile viele Einzelschritte. Für die Öffentlichkeit weitgehend nachrangig wegen deren verständlicher Konzentration auf die Entscheidungsturbulenzen sich häufender ,Rettungs-Gipfel', auf den gigantisch anwachsenden Umfang der Garantien (Briefmarkensammler an Werte aus dem Jahre 1923 erinnernd ${ }^{1}$ und Skeptiker an der Ernsthaftigkeit der Zusagen zweifeln lassend), auf den Bonitätsvergleich der politischen Kulturen der Mitgliedstaaten sowie auf Regierungswechsel in den Eurostaaten vollzieht sich eine Akzentverschiebung in der Entwicklung der rechtlichen Integrationsfundamente - mithin im verbindlichen Erfahrungsspeicher der normpraktischen transnationalen Vernunft. Dies betrifft zwar nicht den verlässlichen Binnenmarkt, wohl aber den daneben zentral gewordenen zweiten Bereich des inneren Zusammenhalts der Union, ${ }^{2}$ die Wirtschafts- und Währungsunion. ${ }^{3}$ Um diesen Vorgang in seinen rechtlichen und politischen Implikationen skizzenhaft zu vermessen, ist als Ausgangspunkt kurz das für Budgethilfen einschlägige geltende europäische Primärrecht der Wirtschaftsund Währungsunion zu erinnern, um sodann die kategorial wesentlichen Budgethilfenschritte seit Mai 2010 in ihrer Rechtsnatur näher zu analysieren und die dadurch eröffneten rechtspolitischen Problemperspektiven grob zu konturieren.

\section{Der einschlägige primärrechtliche Acquis der Wirtschafts- und Währungsunion}

Der Unionsvertrag zählt unter dem Dach der Leitzieltrias der Union in Art. 3 Abs. 1 des Vertrags über die Europäische Union (EUV) (Förderung des Friedens, ihrer Werte und des Wohlergehens ihrer Völker) vier operative Hauptziele auf. Zu ihnen gehört neben der grundsichernden Errichtung des Binnenmarktes, der darauf aufbauenden Entwicklung des sogenannten „Raums der Freiheit, der Sicherheit und des Rechts“ und der Verwirklichung eines unional gemeinsamen auswärtigen Handelns die Errichtung einer Wirtschafts- und Währungsunion. ${ }^{4}$

* Prof. Dr. habil. Dr. h.c. mult. Peter-Christian Müller-Graff, Universität Heidelberg.

Der Text ist die erweiterte Fassung des Vortrags des Verfassers auf der Sitzung des Wissenschaftlichen Direktoriums des Instituts für Europäische Politik in Berlin am 6. Oktober 2011. Siehe dazu den Tagungsbericht Moritz Eckert/Insa Nieberg: Deutschlands Rolle in Europa: Führungsmacht oder Vetospieler?, in diesem Band, S. 349-356.

1 So wurde etwa ein Brief von Ringler \& Recknagel in Elberfeld am 28. November 1923 mit 20 beziehungsweise 80 Milliarden Mark frankiert. Abrufbar unter: http://www.briefmarken-ausstellung.de/infla/brief25/html (letzter Zugriff: 06.12.2011).

2 Zu Elementen des Zusammenhalts vgl. Peter-Christian Müller-Graff (Hrsg.): Der Zusammenhalt Europas - In Vielfalt geeint, Baden-Baden 2009.

3 Zum Zusammenhaltsaspekt der Währungsunion vgl. Wim Koesters/Tobias Zimmermann: Integrative und trennende Wirkungen der europäischen Währungsunion, in: Peter-Christian Müller-Graff (Hrsg.): Der Zusammenhalt Europas, Baden-Baden 2009, S. 43-54; zum Binnenmarkt vgl. André Schmidt: Die Integrationskraft des Europäischen Binnenmarktes, in: Peter-Christian Müller-Graff (Hrsg.): Der Zusammenhalt Europas, Baden-Baden 2009, S. 23-42. Art. 3 Abs. 4 EUV. 


\section{Die primärrechtliche Grundstruktur}

Die primärrechtliche Grundstruktur der Wirtschafts- und Währungsunion findet sich verteilt in dem zentralen (technokratisch unschön so bezeichneten) Vertrag über die Arbeitsweise der Europäischen Union (AEUV) und hier in dessen Vorschriften über die internen Politiken und Maßnahmen der Union unter dem Titel „Die Wirtschafts- und Währungspolitik ${ }^{* 5}$ und in den rechtlich gleichrangigen einschlägigen Protokollen. ${ }^{6} \mathrm{Zu}$ letzteren gehören namentlich diejenigen über die Konvergenzkriterien, über das Verfahren bei einem übermäBigen Defizit, über die Satzung des Europäischen Systems der Zentralbanken (ESZB) und der Europäischen Zentralbank (EZB) und über die Euro-Gruppe. Während danach die Tätigkeit der Mitgliedstaaten und der Union im Sinne des erwähnten allgemeinen Zielartikels die Einführung einer Wirtschaftspolitik umfasst, die auf den drei Säulen der „Koordinierung der Wirtschaftspolitik der Mitgliedstaaten, dem Binnenmarkt und der Festlegung gemeinsamer Ziele beruht und dem Grundsatz einer offenen Marktwirtschaft mit freiem Wettbewerb verpflichtet ist", 7 erstreckt sie sich nach Art. 119 Abs. 2 AEUV zugleich auf eine einheitliche Währung ,,sowie die Festlegung und Durchführung einer einheitlichen Geld- sowie Wechselkurspolitik, die beide vorrangig das Ziel der Preisstabilität verfolgen und unbeschadet dieses Zieles die allgemeine Wirtschaftspolitik in der Union unter Beachtung des Grundsatzes einer offenen Marktwirtschaft mit freiem Wettbewerb unterstützen sollen." Als einzuhaltende, so bezeichnete ,richtungsweisende Grundsätze“ benennt der Vertrag hierfür ausdrücklich: stabile Preise, gesunde öffentliche Finanzen und monetäre Rahmenbedingungen sowie eine dauerhaft finanzierbare Zahlungsbilanz. ${ }^{8}$ So sehr damit ein rechtskategorialer Gleichklang angestimmt zu sein scheint, teilen sich doch die nachfolgenden Vorschriften in eine eher intergouvernemental-supranational kombinierte Wirtschaftsunion und eine supranational fixierte Währungsunion auf.

\section{Die intergouvernemental-supranationale Wirtschaftsunion}

Die Regeln über die Wirtschaftsunion ${ }^{9}$ werden gemeinhin als intergouvernemental verstanden, enthalten jedoch auch einige supranationale Elemente (namentlich Mehrheitsentscheidungen des Rates, die teilweise Verfügbarkeit der klassisch supranationalen Handlungsinstrumente der Union sowie die teilweise Zuständigkeit des Europäischen Gerichtshofes, EuGH).

Intergouvernementaler Rahmen: Normkonzeptionelle Grundlage der Wirtschaftsunion ist allerdings zuallererst, dass das Primärrecht grundsätzlich von den Wirtschaftspolitiken der Mitgliedstaaten ausgeht (unbeschadet einer Wirtschaftspolitik der Union) und diese einer unionsrechtlichen Koordinierungspflicht unterwirft. So legt Art. 121 AEUV in klassischer Formulierung intergouvernementalen Zusammenwirkens ähnlich derjenigen in der ursprünglichen dritten Säule des Maastrichter Unionsvertrags im Bereich Justiz und Inneres ${ }^{10}$ fest, dass die Mitgliedstaaten ihre Wirtschaftspolitik, ,als eine Angelegenheit von gemeinsa-

\section{Art. 119 bis 144 AEUV.}

6 Vgl. Art. 51 EUV, wonach Protokolle und Anhänge der Verträge Bestandteil der Verträge sind.

7 Art. 119 Abs. 1 AEUV. Zu den wirtschaftsordnungsrechtlichen Konsequenzen im Licht der Lissabonner Neuerungen vgl. soeben Peter-Christian Müller-Graff: Soziale Marktwirtschaft als neuer Primärrechtsbegriff der Europäischen Union, in: Peter-Christian Müller-Graff/Stefanie Schmahl/Vassilios Skouris (Hrsg.): Europäisches Recht in Bewährung und Wandel. Festschrift für Dieter H. Scheuing, Baden-Baden 2011, S. 600-623.

8 So ausdrücklich Art. 119 Abs. 3 AEUV.

9 Art. 120 bis 126 AEUV.

10 Vgl. die Formulierung in Art. K.1 EUV (Maastrichter Fassung): ,Zur Verwirklichung der Ziele der Union [...] betrachten die Mitgliedstaaten [...] folgende Bereiche als Angelegenheiten von gemeinsamem Interesse“. 
mem Interesse" betrachten und diese im Rat koordinieren. Auch sieht das Koordinierungsverfahren mit der „Empfehlung“"11 oder „Stellungnahme“"12 mehrfach ein Handlungsinstrument der Union vor, das in Art. 288 Abs. 5 AEUV ausdrücklich als ,nicht verbindlich“ bezeichnet wird. Daneben kann es im Koordinierungsverfahren der Wirtschaftspolitik und/ oder im Verfahren zur Überwachung der Haushaltsdisziplin zu gleichermaßen rechtlich unverbindlichen Berichterstattungen ${ }^{13}$ und Schlussfolgerungen, ${ }^{14}$ Überwachungen ${ }^{15}$ und Gesamtbewertungen, ${ }^{16}$ Unterrichtungen ${ }^{17}$ und Verwarnungen, ${ }^{18}$ Veröffentlichungen ${ }^{19}$ und Ersuchen $^{20}$ kommen. Ein Vertragsverletzungsverfahren vor dem EuGH ist hinsichtlich der mitgliedstaatlichen Pflicht zur Vermeidung übermäßiger öffentlicher Defizite und in den ersten Etappen des Verfahrens zur Haushaltsüberwachung ausdrücklich ausgeschlossen. ${ }^{21}$

Supranationale Elemente: Immerhin können aber Einzelheiten des Koordinierungsverfahrens im ordentlichen Gesetzgebungsverfahren durch Verordnungen (im Sinne des Art. 288 Abs. 2 AEUV) festgelegt werden. ${ }^{22}$ Im Überwachungsverfahren der Haushaltsdisziplin sind in verschiedenen Etappen verbindliche Beschlüsse des Rates (im Sinne des Art. 288 Abs. 4 AEUV) möglich ${ }^{23}$ und der Rat kann sogar gemäß einem besonderen Gesetzgebungsverfahren Bestimmungen erlassen, die das Protokoll über das Verfahren bei einem übermäßigen Defizit ablösen. ${ }^{24}$ In den speziellen Beistandsverfahren nach Art. 122 AEUV sind jedenfalls Beschlüsse möglich ${ }^{25}$ (unklar ist, ob auch Verordnungen wie die - noch zu behandelnde - Verordnung des Rates vom 10. Mai 2010 zur Einführung eines europäischen Finanzstabilisierungsmechanismus ${ }^{26}$ ). Auch besteht keine Beschränkung der verfügbaren Handlungsformen für den Rat bei der näheren Begriffsdefinition der Verbote der Art. 123 bis 125 AEUV (Verbot für Kreditfazilitäten für öffentliche Einrichtungen; Verbot bevorrechtigten Zugangs zu den Finanzinstituten; Haftungsausschlüsse und Schuldeintrittsverbote von Union und Mitgliedstaaten). ${ }^{27}$ Schließlich ist die Jurisdiktion des EuGH außerhalb der

11 Vgl. Art. 121 Abs. 2 S. 1 AEUV (Kommission) und Art. 121 Abs. 2 S. 3 AEUV (Rat); Art. 121 Abs. 4 AEUV (Rat); siehe auch im Verfahren zur Überwachung der Haushaltsdisziplin Art. 126 Abs. 7 AEUV (Kommission, Rat); Art. 126 Abs. 13 AEUV (Kommission).

12 Vgl. Art. 126 Abs. 4 AEUV (Wirtschafts- und Finanzausschuss) und Art. 126 Abs. 5 AEUV (Kommission).

13 Vgl. Art. 121 Abs. 2 S. 1 AEUV (Rat an Europäischen Rat über Entwurf der Grundzüge der Wirtschaftspolitik der Mitgliedstaaten und der Union); Art. 121 Abs. 5 AEUV (Präsident des Rates und Kommission an das Europäische Parlament über die Ergebnisse der multilateralen Überwachung); siehe auch im Verfahren zur Überwachung der Haushaltsdisziplin Art. 126 Abs. 3 AEUV (Kommission über Verfehlung der Kriterien zur Einhaltung der Haushaltsdisziplin).

14 Vgl. Art. 121 Abs. 2 S. 2 AEUV (Europäischer Rat).

15 Vgl. Art. 121 Abs. 3 AEUV (Rat überwacht die wirtschaftliche Entwicklung in jedem Mitgliedstaat und in der Union); Art. 126 Abs. 2 AEUV (Kommission überwacht Entwicklung der Haushaltslage und Höhe des öffentlichen Schuldenstandes in den Mitgliedstaaten im Hinblick auf die Feststellung schwerer Fehler).

16 Vgl. Art. 121 Abs. 3 AEUV (Rat)

17 Vgl. Art. 121 Abs. 2 S. 3 AEUV (Europäischer Rat an Europäisches Parlament); Art. 126 Abs. 5 AEUV (Kommission an Rat)

18 Vgl. Art. 121 Abs. 4 AEUV (Kommission).

19 Vgl. Art. 121 Abs. 4 AEUV (Rat); Art. 126 Abs. 8 AEUV (Rat).

20 Vgl. Art. 126 Abs. 9 AEUV (Rat ersucht Mitgliedstaaten um Berichte zur Überprüfung der Anpassungsbemühungen).

21 Vgl. Art. 126 Abs. 10 AEUV (Ausschluss hinsichtlich Art. 126 Abs. 1 bis 9 AEUV).

22 Vgl. Art. 121 Abs. 6 AEUV.

23 Vgl. Art. 126 Abs. 6, 9, 11, 12 AEUV (Rat).

24 Vgl. Art. 126 Abs. 14 S. 2 AEUV.

25 Vgl. Art. 121 Abs. 1 und 2 AEUV.

26 Verordnung (EU) Nr. 407/2010 des Rates vom 11. Mai 2010 zur Einführung eines europäischen Finanzstabilisierungsmechanismus, in: Amtsblatt der EU, Nr. L 118 vom 12. Mai 2010, S. 1-4.

27 In der Rechtsform zulässig daher die darauf gestützte Verordnung (EG) Nr. 3603/93 des Rates vom 13. Dezember 1993 zur Festlegung der Begriffsbestimmung für die Anwendung der in Artikel 104 und Artikel 104b Absatz 1 des Vertrages vorgesehenen Verbote, in: Amtsblatt der EU, Nr. L 332 vom 31. Dezember 1993, S. 1-3. 
genannten Beschränkung bei Vertragsverletzungsverfahren nicht ausgeschlossen, insbesondere auch nicht die (bereits einmal zwischen Kommission und Rat erprobte ${ }^{28}$ ) Zuständigkeit für Nichtigkeitsklagen gegen bestimmte Handlungen von Unionsorganen (einschließlich der $\mathrm{EZB}^{29}$ ) und sonstigen Unionsstellen.

\section{Die supranationale Währungsunion}

Im Kontrast zur rechtskategorialen Ausgestaltung der Wirtschaftsunion geht es im Primärrecht der Währungspolitik ${ }^{30}$ nicht um eine Koordinierung mitgliedstaatlicher Politiken, sondern um die supranationale Gestaltung und Durchführung der Währungsunion. Folgerichtig definiert das Primärrecht zuallererst in seiner Ankernorm der Währungspolitik das vorrangige Ziel des ESZB. Es bestimmt dazu die Gewährleistung der Preisstabilität ${ }^{31}$ und lässt eine Unterstützung der ,allgemeine[n] Wirtschaftspolitik in der Union“ durch das ESZB nur zu, ,soweit dies ohne Beeinträchtigung des Zieles der Preisstabilität möglich ist."32 Darauf sind die weiteren Vorschriften des Primärrechts, namentlich die Rechte der EZB einschließlich ihrer Befugnis zum Erlass von Verordnungen und Beschlüssen, ${ }^{33}$ ausgerichtet und sind einschlägige Normen des Sekundärrechts auszurichten.

\section{Die Rechtsnatur der Maßnahmen der Euroraum-Budgethilfenpolitik seit 2010}

Wendet man sich vor dem Hintergrund dieser Skizze der Frage nach der Zuordnung der Rechtsnatur der Euroraum-Budgethilfenpolitik seit Mai 2010 zu, so kommen insbesondere fünf konsekutive Schritte sowie die Begleitmaßnahmen der EZB in den Blick. Die Rechtstechnik, Rechtsqualität und Rechtsprobleme dieser Hilfen sind unterschiedlich. Zu unterscheiden sind nachfolgend erstens die Griechenland-Hilfe, zweitens der sogenannte Euro-Rettungsschirm aus Europäischem Finanzstabilisierungsmechanismus (EFSM) und Europäischer Finanzstabilitätsfazilität (EFSF), drittens die erweiterte EFSF, viertens die primärrechtspolitische Absicherung eines dauerhaften Stabilisierungsmechanismus, fünftens der projektierte Europäische Stabilitätsmechanismus (ESM) sowie schließlich die Finanzierungstechniken der EZB. Von dieser Budgethilfenpolitik operativ unterscheidbar ist die sogenannte Sixpack-Initiative der Kommission, die präventiv dem Eintritt von Problemlagen effektiver vorbeugen will.

\section{Der Griechenland-Hilfsbeschluss vom 7. Mai 2010}

Der Griechenland-Hilfsbeschluss vom 7. Mai 2010 beruht nicht auf Unionsrecht. Es handelt sich vielmehr um eine intergouvernementale Erklärung der Staats- und Regierungschefs des Euro-Währungsgebiets, ${ }^{34}$ die zu einer Vereinbarung vom 8. Mai 2010 mit Griechenland über eine Darlehensfazilität führte. Darin stellen sie Griechenland 80 Milliarden Euro zur Verfügung, ,die in ein mit dem IWF geschnürtes Gesamtpaket von 110 Mrd. EUR einfließen. “35

28 Vgl. EuGH Rs. C-27/04 (Kommission/Rat), Slg. 2004, I-6649; dazu Rüdiger Bandilla: Ist der Stabilitäts- und Wachstumspakt rechtlich durchsetzbar? Anmerkungen zum Urteil des Gerichtshofes in der Rechtssache Kommission/Rat (C-27/04), in: Charlotte Gaitanides/Stefan Kadelbach/Gil Carlos Rodriguez Iglesias (Hrsg.): Europa und seine Verfassung. Festschrift für Manfred Zuleeg, Baden-Baden 2005, S. 538-549.

29 Vgl. zum Beispiel Rüdiger Bandilla, in: Eberhard Grabitz/Meinhard Hilf (Hrsg.): EU-Kommentar, München (Loseblattsammlung), Art. 101, Rdz. 3; Doris Hattenberger, in: Jürgen Schwarze (Hrsg.): EU-Kommentar, 2. Aufl., Baden-Baden 2009, Art. 101 EGV, Rdz. 2 a.E.

30 Art. 127 bis 133 AEUV.

31 Vgl. Art. 127 Abs. 1 S. 1 AEUV.

32 Vgl. Art. 127 Abs. 1 S. 2 AEUV.

33 Vgl. Art. 132 AEUV.

34 Erklärung der Staats- und Regierungschefs des Euro-Währungsgebietes, Brüssel, den 7. Mai 2010.

35 Ebenda. 
Die Vereinbarkeit dieses freiwilligen Budgetbeistands mit dem primärrechtlichen Ausschluss von Haftung und Schuldeintritt in Art. 125 AEUV (in der Diskussion meist englisch unklar und missverständlich ,Bail-out-Verbot ${ }^{6}$ genannt) ist bekanntlich umstritten, ${ }^{36}$ aber sowohl wegen des Wortlauts der Vorschrift als auch wegen dessen Normzweckkontexts zu bejahen. ${ }^{37}$ Der Wortlaut schließt Haftung und Schuldeintritt für einen Mitgliedstaat (gegenüber Dritten) durch Union und Mitgliedstaaten aus (,,haftet nicht [...] und tritt nicht [...] ein“38), nicht aber enthält er eine Souveränitätsbeschränkung der Mitgliedstaaten, einen anderen Mitgliedstaat im Innenverhältnis freiwillig durch Budgethilfen zu unterstützen. Der unmittelbare Normzweck ist zweifellos die Sicherung der Selbstdisziplinierung und des Selbstverantwortungsbewusstseins jedes Mitgliedstaates in seiner Wirtschafts- und Haushaltspolitik. ${ }^{39}$ Danach hat kein Mitgliedstaat Anspruch auf Hilfe und bei dessen Versagen kein Dritter Durchgriff auf die Union oder die anderen Mitgliedstaaten. Allerdings steht die Vorschrift im übergreifenden Kontext des Zieles einer stabilen Wirtschafts- und Währungsunion. ${ }^{40}$ Gerät diese trotz aller primärrechtlichen Vorkehrungen durch Disziplinlosigkeit eines oder mehrerer Mitgliedstaaten in Turbulenzen, wäre es zu diesem übergreifenden Ziel sinnwidrig, einem Eurostaat zu verwehren, die ihn selbst (seine ,eigene "Währung) betreffende Gemeinschaftswährung durch Budgethilfen an einen Problemstaat des Euroraums zu stabilisieren.

Die intergouvernementale Erklärung hat in Deutschland noch am 7. Mai 2010 zum Erlass des Gesetzes ,zur Übernahme von Gewährleistungen zum Erhalt der für die Finanzstabilität in der Währungsunion erforderlichen Zahlungsfähigkeit der Hellenischen Republik“ (kürzer: Währungsunion-Finanzstabilitätsgesetz) geführt. ${ }^{41}$ Es enthält eine Ermächtigung des Bundesfinanzministeriums, Gewährleistungen für Kredite der Kreditanstalt für Wiederaufbau (KfW) an Griechenland bis zu 22,4 Milliarden Euro (Zinsen und Kosten nicht eingerechnet) zu übernehmen. Soweit Griechenland auf dieser Grundlage Geld erhält, handelt es sich um einen rückzahlbaren Kredit und wird die KfW in dieser Höhe zum Gläubiger der Rückzahlungsforderung. Das Bundesverfassungsgericht hat am 7. September 2011 den Mechanismus dieses Gesetzes als hinreichend vorhersehbar und begrenzt beurteilt und daher als parlamentarisch verantwortbar und vereinbar mit dem Grundgesetz bewertet. ${ }^{42}$

Der sogenannte Euro-Rettungsschirm aus Europäischem Finanzstabilisierungsmechanismus und europäischer Finanzstabilitätsfazilität

Der sogenannte Euro-Rettungsschirm aus EFSM und EFSF besteht aus einer Mischkonstruktion aus Unionsrecht sowie intergouvernementaler Absprache und nationalem Recht.

36 Vgl. als vorbereitende Aufarbeitung des Diskussionsstandes vor Gewährung der Griechenland-Hilfe Kristin Rohleder/Olaf Zehnpfund/Lena Sinn: Bilaterale Finanzhilfen für Griechenland. Vereinbarkeit mit Artikel 125 des Vertrages über die Arbeitsweise der Europäischen Union, Deutscher Bundestag. Wissenschaftliche Dienste: Infobrief, WD 11 - 3000 - 103/10.

37 Vgl. dazu Peter-Christian Müller-Graff: Vertragskonforme Rettung der Währungsunion?, in: Europäisches Wirtschafts- und Steuerrecht 9/2011, S. I; Peter-Christian Müller-Graff: Die Europäische Wirtschafts- und Währungsunion: Rechtliche Rahmendaten für Reformen, in: Stefan Bechtold/Joachim Jickeli/Mathias Rohe (Hrsg.): Recht, Ordnung und Wettbewerb. Festschrift für Wernhard Möschel, Baden-Baden 2011, S. 885-900.

38 Art. 125 Abs. 1 S. 1 AEUV.

39 Statt aller Ernest Gnan, in: Hans von der Groeben/Jürgen Schwarze (Hrsg.): Vertrag über die Europäische Union und Vertrag zur Gründung der Europäischen Gemeinschaft. Kommentar, 6. Aufl., Baden-Baden 2003, Art. 103 EGV, Rdz. 2ff.

40 Art. 119 Abs. 3 AEUV.

41 BGB1. I 2010, S. 537.

42 Bundesverfassungsgericht 2BvR 987/10, 2BvR 1485/10, 2 BvR 1099/10, Tz. 119ff.; dazu Peter-Christian Müller-Graff: L'arrêt de Karlsruhe sur les aides budgétaires dans la zone Euro, in: Regards sur l'Economie Allemande 102/2011, S. 5-14. 
Europäischer Finanzstabilisierungsmechanismus: Der ,Rettungsschirm“ beruht erstens als EFSM auf Unionsrecht, genauer auf der Verordnung zur Einführung eines europäischen Finanzstabilisierungsmechanismus vom 11. Mai 2010. ${ }^{43}$ Sie ist auf die Kompetenz des Art. 122 Abs. 2 AEUV gestützt, die - unabhängig von der Zugehörigkeit zum Euroraum - einen finanziellen Beistand der Union zulässt, wenn ein ,Mitgliedstaat aufgrund von [...] außergewöhnlichen Ereignissen, die sich seiner Kontrolle entziehen, von Schwierigkeiten betroffen oder von gravierenden Schwierigkeiten ernstlich bedroht" ${ }^{\star 44}$ ist. Die Verordnung wiederholt diese Voraussetzungen in ihrem Art. 1. Deren Vorliegen bei Budgetproblemen infolge selbst zu verantwortender Schuldenaufnahme ist jedoch abzulehnen, ${ }^{45}$ mag aber in der Ersterfahrungslage der realen und plötzlichen Krisenkonsequenzen solchen Verhaltens im Frühjahr 2010 vorübergehend grenzwertig bejaht werden - gewiss aber nicht künftig in derart aus budgetärer Disziplinlosigkeit verursachten Schwierigkeiten. Der Hinweis auf ,,[d]ie beispiellose Weltfinanzkrise“ im dritten Erwägungsgrund ${ }^{46}$ verschleiert die von den betroffenen Mitgliedstaaten für deren Schwierigkeiten selbst gesetzte und zu verantwortende Ursache unsolider Haushaltspolitik. Allein deshalb, also wegen des fortgesetzten Geldbedarfs für Maßnahmen, die sich ein Staat nicht aus eigenen Einnahmen oder Vermögensveräußerungen leisten kann, gerät ein Staat in Schwierigkeiten am Kapitalmarkt. Nicht der Markt ist das Problem, sondern die staatliche Haushaltspolitik.

Die Frage, ob Art. 122 Abs. 2 AEUV überhaupt den Erlass einer Verordnung ermöglicht, lässt sich bejahen, da der Vertrag weder eine bestimmte rechtliche Maßnahmeart vorsieht (wie etwa Artt. 50,115 AEUV die Richtlinie) noch ausschließt. Technisch ermöglicht der EFSM einen konditionierten finanziellen Beistand in Form eines Darlehens oder einer Kreditlinie durch Ratsbeschluss mit qualifizierter Mehrheit ${ }^{47}$ (also gegebenenfalls auch gegen das Votum des deutschen Ratsmitglieds) auf Vorschlag der Kommission bis zur Höhe der Eigenmittel der Union ${ }^{48}$ (das sind 60 Milliarden Euro). Problematisch und judikativ ungeklärt ist allerdings mit Blick auf das haushaltsrechtliche Gebot der Eigenmittelfinanzierung ${ }^{49}$ und auf die Unionskompetenzen die hierfür der Kommission eingeräumte Ermächtigung, auf den Kapitalmärkten oder bei Finanzinstituten im Namen der Union Anleihen aufzunehmen..$^{50}$ Anderes mag für die sogenannte Abrundungsermächtigung gelten, ${ }^{51}$ doch bedürfte auch dies genauerer Prüfung. ${ }^{52}$ Im Rahmen dieses Mechanismus werden nicht die

43 Verordnung (EU) Nr. 407/2010 des Rates, 2010.

44 Art. 122 Abs. 2 AEUV.

45 So auch etwa Martin Seidel: Europarechtsverstöße und Verfassungsbruch im Doppelpack, in: Europäische Zeitschrift für Wirtschaftsrecht 7/2011, S. 241.

46 3. Erwägungsgrund der Verordnung (EU) Nr. 407/2010 des Rates, 2010.

47 Art. 3 Abs. 2 der Verordnung (EU) Nr. 407/2010 des Rates, 2010.

48 Art. 2 Abs. 1 S. 1 und Abs. 2 sowie Art. 3 Abs. 2 der Verordnung (EU) Nr. 407/2010 des Rates, 2010.

49 Art. 311 Abs. 1 AEUV.

50 Art. 2 Abs. 1 S. 2 der Verordnung (EU) Nr. 407/2010 des Rates, 2010; kritisch dazu auch Seidel: Europarechtsverstöße und Verfassungsbruch im Doppelpack, 2011.

51 Art. 352 AEUV. Deren von der Einstimmigkeit im Rat abhängende Nutzbarkeit unterliegt allerdings seit dem Lissabon-Urteil des Bundesverfassungsgerichts (BVerfGE 123, 267) und des daraufhin erlassenen $\S 8$ des Gesetzes über die Wahrnehmung der Integrationsverantwortung des Bundestages und des Bundesrates in Angelegenheiten der Europäischen Union (Integrationsverantwortungsgesetz - IntVG) vom 22. September 2009 (BGB1. 2009 I, S. 3022) wegen des darin ausgesprochenen Erfordernisses eines zustimmenden Gesetzes gemäß Art. 23 Abs. 1 Grundgesetz dem Gesetzesvorbehalt des Bundestages mit Zustimmung des Bundesrates. Dem deutschen Vertreter im Rat ist danach von Verfassungs und Gesetzes wegen untersagt, ohne ein derartiges, vorweg in Kraft getretenes Gesetz im Rat einem Vorschlag zuzustimmen oder sich bei einer Beschlussfassung zu enthalten. Vgl. dazu im Einzelnen Hannes Rathke: Flexibilitätsklausel, in: Andreas von Arnauld/Ulrich Hufeld (Hrsg.): Systematischer Kommentar zu den Lissabon-Begleitgesetzen - IntVG/EUZBBG/EUZBLG, Baden-Baden 2011, S. 248-252.

52 Genutzt für Art. 1 Abs. 2 der Verordnung (EG) Nr. 332/2002 des Rates vom 18. Februar 2002 zur Einführung einer Fazilität des mittelfristigen finanziellen Beistands zur Stützung der Zahlungsbilanzen der Mitgliedstaaten außerhalb des Eurogebietes, in: Amtsblatt der EU, Nr. L 53 vom 23. Februar 2002, S. 1-3. 
Mitgliedstaaten Gläubiger des bedürftigen Mitgliedstaates und Schuldner der Refinanzierungsgläubiger, sondern die Union.

Europäische Finanzstabilisierungsfazilität (EFSF): Zur Komplettierung des ,Rettungsschirms “ ist der Verordnung ein intergouvernementaler „Beschluss der im Rat der EU vereinigten Vertreter der Regierungen der dem Euro-Währungsgebiet angehörenden Mitgliedstaaten“ vom 10. Mai $2010^{53}$ über eine EFSF beigesellt, in dem diese zusagen, über eine auf drei Jahre befristete - ,Zweckgesellschaft“ „Beistand zu leisten, für die die teilnehmenden Mitgliedstaaten [...] entsprechend ihrem Anteil an dem eingezahlten Kapital der Europäischen Zentralbank [...] bis zu einem Volumen von 440 Mrd. EUR bürgen“. ${ }^{54}$ Bürgschaft ist noch keine Zahlung. Dazu wurde die EFSF als société anonyme (Aktiengesellschaft) in Luxemburg, also als privatrechtliche Organisation, zum Zweck der Gewährung von „Stabilitätshilfen" (Darlehen) an notleidende Eurostaaten errichtet und mit dieser und zwischen den Eurostaaten ein umfänglicher, rechtlich hochtechnisierter Rahmenvertrag abgeschlossen ${ }^{55}$ (mit den Eurostaaten als „Gesellschafter“56), in dem sich unter anderem namentlich die Regeln über die Darlehensvergabe ${ }^{57}$ und die Bürgschaftsfolgen (Eintritt und Regress) finden. Dies ist kein völkerrechtlicher Vertrag, da er nicht dem Völkerrecht, sondern einem nationalen Recht und zwar höchst erstaunlich und politisch diskussionsbedürftig dem englischen (!) Recht und dessen Auslegung unterstellt ist. ${ }^{58}$ Die vereinbarte gerichtliche Zuständigkeit ist gespalten: für Streitigkeiten zwischen einem oder mehreren Eurostaaten und der EFSF gilt die ausschließliche Gerichtsbarkeit der Gerichte Luxemburgs, ${ }^{59}$ für Streitigkeiten ausschließlich zwischen den Eurostaaten die ausschließliche Gerichtsbarkeit des EuGH. ${ }^{60}$ Die Einsetzung des EuGH ist legitimatorisch als ein seitens des Unionsrechts kompetenziell zulässiger Schiedsvertrag61 anzusehen.

Der Rahmenvertrag sieht weitere Verbindungen zu Organen der Union vor, so etwa: bei der Verhandlung und Unterzeichnung der „Absichtserklärung“ (,Memorandum of Understanding" $)^{62}$ mit dem jeweiligen Darlehensnehmer zur Kommission als Bevollmächtigte; ${ }^{63}$ vor der Auszahlung eines Darlehens zur Kommission (in Abstimmung mit der EZB und der Eurogruppen-Arbeitsgruppe); ${ }^{64}$ bei Berechnungsfragen im Auftragswege zur Europäischen

53 Vgl. Rat der Europäischen Union: Beschluss der im Rat der Europäischen Union vereinigten Vertreter der Regierungen der dem Euro-Währungsgebiet angehörenden Mitgliedstaaten; Beschluss der Vertreter der Regierungen der 27 EU-Mitgliedstaaten, Dok. 9614/10.

54 Ebenda.

55 EFSF Rahmenvertrag zwischen Königreich Belgien, Bundesrepublik Deutschland, Irland, Königreich Spanien, Französische Republik, Italienische Republik, Republik Zypern, Großherzogtum Luxemburg, Republik Malta, Königreich der Niederlande, Republik Österreich, Portugiesische Republik, Republik Slowenien, Slowakische Republik, Republik Finnland, Hellenische Republik und European Financial Stability Facility, 7. Juni 2010.

56 Die Eurostaaten bezeichnen sich selbst und die EFSF im Partnerchapeau des Vertrags unter (A) vertragskategorial zutreffend als „Gesellschafter der EFSF“.

57 Vgl. als Beispiel der Konditionen etwa das schon auf die erweiterte EFSF bezogene Angebot einer neuen Vereinbarung über eine Finanzfazilität über 3 Milliarden Euro an Irland. Vgl. Europäische Kommission: Mitteilung an die Kommission. Wesentliche Bedingungen der EFSF-Finanzhilfevereinbarung mit Irland, SEK (2011) 1272.

58 Vgl. Ziff. 16 Abs. 1 des EFSF Rahmenvertrags. Völkerrechtliche Verträge sind nach herkömmlicher Definition nur solche, die dem Völkerrecht unterliegen. Vgl. Wolff Heintschel von Heinegg: Die völkerrechtlichen Verträge als Hauptrechtsquelle des Völkerrechts, in: Knut Ipsen: Völkerrecht, 3. Aufl., München 1990, S. 94-187, hier S. 100.

59 Vgl. Ziff. 16 Abs. 2 S. 2 des EFSF Rahmenvertrags.

60 Vgl. Ziff. 16 Abs. 2 S. 3 des EFSF Rahmenvertrags.

61 Schiedsvertrag im Sinne der Voraussetzungen des Art. 273 AEUV

62 Vgl. 2. Erwägungsgrund in der Präambel des EFSF Rahmenvertrags.

63 Vgl. Ziff. 2 Abs. 1 des EFSF Rahmenvertrags; Unterzeichnungsvollmacht nur nach Genehmigung durch die Eurogruppen-Arbeitsgruppe. Parallel dazu die Unterzeichnungsvollmacht für die Kommission im Falle einer Änderung der „Absichtserklärung“, der die Eurostaaten zugestimmt haben. Vgl. Ziff. 9 Abs. 4 ESMV.

64 Vgl. Ziff. 3 Abs. 1 des EFSF Rahmenvertrags. 
Investitionsbank (EIB) oder zu ,,jeder beliebigen sonstigen, einstimmig von den Sicherungsgebern genehmigten Agentur, Anstalt, Institution der EU“;65 bei der Verletzung der Bestimmungen einer Vereinbarung oder bei Änderungserfordernissen informatorisch zur Eurogruppen-Arbeitsgruppe, Kommission und EZB; ${ }^{66}$ für die Wahrnehmung bestimmter Verwaltungsaufgaben gegebenenfalls auftragsweise zur EIB oder zu sonstigen Behörden, Anstalten und Institutionen der Europäischen Union ${ }^{67}$ und für Zahlungsaufgaben zur EZB. ${ }^{68}$

Der intergouvernementale Beschluss der Eurostaaten hat in Deutschland zum Erlass eines weiteren Gesetzes geführt: des Gesetzes ,zur Übernahme von Gewährleistungen im Rahmen eines europäischen Stabilisierungsmechanismus“ vom 22. Mai 2010 (kürzer: EuroStabilisierungs-Gesetz). ${ }^{69}$ Es enthält eine Ermächtigung des Bundesministeriums der Finanzen für die Kreditaufnahme der Zweckgesellschaft zur Finanzierung von Notmaßnahmen zum Erhalt der Zahlungsfähigkeit des betroffenen Eurostaates Gewährleistungen bis zu 123 Milliarden Euro zu übernehmen (Zinsen und Kosten nicht eingerechnet). Dem Parlamentsvorbehalt des deutschen Verfassungsrechts ist dadurch jedenfalls förmlich Genüge getan, unbeschadet einer genaueren Überprüfung der Ausgestaltung der Arbeitsweise der EFSF im einzelnen. Das Bundesverfassungsgericht hat auch dieses Gesetz nachvollziehbar für verfassungskonform, weil in seinen Wirkungen vorhersehbar und vom Bundestag verantwortbar, erklärt. $^{70}$

\section{Die erweiterte EFSF}

Die erweiterte EFSF ändert nicht das Grundmuster des ,Rettungsschirms` als Kombination aus Unionsrecht, intergouvernementalem Beschluss, Rahmenvertrag und nationalem Gesetz. Der geänderte Rahmenvertrag ${ }^{71}$ erhöht das Volumen für die (jetzt über die Form der Darlehensvergabe hinaus ausgedehnte), Finanzhilfefazilität‘ auf 779,78314 Milliarden Euro (Anteil Deutschlands: 221,0459 Milliarden Euro $^{72}$ ). Er erweitert zugleich die Aktionsformen der EFSF: ihr wird neben der derzeitigen Kreditgewährung auch ermöglicht, Anleihen auf Sekundär- und Primärmärkten zu kaufen, vorbeugende Kreditlinien zu gewähren (,,vorsorgliche Fazilitäten“) sowie Finanzinstitute in einem Eurostaat zu rekapitalisieren (mittels Darlehen an die Regierung, auch in Nicht-Programmstaaten).$^{73}$

65 Vgl. Ziff. 8 Abs. 1 des EFSF Rahmenvertrags.

66 Vgl. Ziff. 9 Abs. 1 und 2 des EFSF Rahmenvertrags.

67 Vgl. Ziff. 12 des EFSF Rahmenvertrags.

68 Ziff. 12 Abs. 2 des EFSF Rahmenvertrags. Vgl. Beschluss der Europäischen Zentralbank vom 21. September 2010 betreffend die Verwaltung von EFSF-Darlehen an Mitgliedstaaten des Euro-Währungsgebiets (EZB/ 2010/15), in: Amtsblatt der EU, Nr. L 253 vom 28. September 2010, S. 58-59; Beschluss der Europäischen Zentralbank vom 20. Dezember 2010 über die Eröffnung von Konten zur Abwicklung von Zahlungen in Verbindung mit Darlehen der EFSF an Mitgliedstaaten, deren Währung der Euro ist (EZB/2010/31), in: Amtsblatt der EU, Nr. L 10 vom 14. Januar 2011, S. 7-8; Beschluss der Europäischen Zentralbank vom 31. Oktober 2011 zur Änderung des Beschlusses EZB/2010/15 betreffend die Verwaltung von EFSF-Darlehen an Mitgliedstaaten des Euro-Währungsgebiets und zur Änderung des Beschlusses EZB/2010/31 über die Eröffnung von Konten zur Abwicklung von Zahlungen in Verbindung mit Darlehen der EFSF an Mitgliedstaaten, deren Währung der Euro ist (EZB/2011/16), in: Amtsblatt der EU, Nr. L 289 vom 8. November 2011, S. 35-36.

69 BGBl. 2010 I, S. 627.

70 Bundesverfassungsgericht 2BvR 987/10, 2BvR 1485/10, 2 BvR 1099/10, Tz.119ff.

71 Ergänzender Änderungsvertrag zum EFSF Rahmenvertrag vom 21. Juli 2011, in Kraft getreten am 18. Oktober 2011; kritisch dazu Oliver Sauer/Bert Van Roosebeke: Intergouvernementale Vereinbarung und nationale Begleitgesetzgebung Reform der Europäischen Finanzstabilisierungsfazilität (EFSF), Centrum für Europäische Politik: CEP-Analyse, 26.09.2011.

72 Vgl. Anlage 1 des geänderten EFSF Rahmenvertrags. Dieser Betrag ist aufgenommen von Art. 1 Ziff. 2 (als $\S 1$ Abs. 1 S. 2) des Gesetzes zur Änderung des Gesetzes zur Übernahme von Gewährleistungen im Rahmen eines europäischen Stabilisierungsmechanismus, in: BGB1. 2011 I, S. 1992.

73 Vgl. 2. Erwägungsgrund der Präambel des geänderten EFSF Rahmenvertrags. 
Auch diese vom Stabilisierungsmechanismus-Änderungsgesetz vom 9. Oktober 2011 übernommene Erweiterung ist im Lichte des Budgethilfen-Urteils des Bundesverfassungsgerichts grundsätzlich als verfassungskonform anzusehen, weil sie nach demselben Muster wie der ursprüngliche Rahmenvertrag begrenzt ausgestaltet ist. Eine Prüfung, ob alle seine Detailregelungen, denen der Bundestag zugestimmt hat, den aus dem Demokratieprinzip abgeleiteten Erfordernissen des Budgethilfe-Urteils entsprechen, kann hier nicht vorgenommen werden. Allerdings nähert sich die schiere Ausweitung des von der Bundesrepublik übernommenen Garantievolumens dem Punkt, an dem das Bundesverfassungsgericht die im Budgethilfenurteil ausgesprochene Selbstbegrenzung seiner Jurisdiktion (in sachgerechter gewaltenteilender Anerkennung des Einschätzungsspielraums und der politischen Verantwortung des Gesetzgebers hinsichtlich der Bewertung des Eintrittsrisikos ${ }^{74}$ der künftigen Tragfähigkeit des Bundeshaushalts und des wirtschaftlichen Leistungsvermögens der Bundesrepublik $^{75}$ ) als überschritten oder die Kontrollierbarkeit des Beistandsmechanismus als nicht mehr gewährleistet ${ }^{76}$ sehen könnte. ${ }^{77}$ Hebelungen zur Ausweitung des Aktionsvolumens der $\mathrm{EFSF}^{78}$ (zum Beispiel Versicherungslösungen, unbegrenzte Kreditlinien bei der EZB, eine banklizenzermöglichte Fazilitätshebelung bei der EZB durch Anleihenhinterlegung oder die Gründung einer Zweckgesellschaft zum Staatsanleihenkauf mit Verbriefungsfinanzierung) erhöhen nicht das Volumen der rechtlichen Bürgschaftsverpflichtung, möglicherweise aber das Risiko des Eintritts des Gewährleistungsfalles. Jenseits der Rechtsfragen verwundert freilich, dass mit der Hoffnung auf Hebelungsmodelle und Geldmengenvermehrung anscheinend das Problem der Maßlosigkeit, das zur Finanzmarktkrise 2008 führte, in diesem Fall als beherrschbar angesehen wird, es sei denn, die Ausweitungsperspektive ist ein resignativer Vorbote einer schwerwiegenden Zäsur des Geldwerts unter dem Druck der Konsequenzen des anscheinend nicht hinreichend disziplinierbaren öffentlichen Haushaltswesens.

Die primärrechtspolitische Absicherung der Einrichtung eines dauerhaften Stabilitätsmechanismus: der projektierte vertragsändernde Art. 136 Abs. 3 AEUV

Wieder eine andere Rechtsebene ist auf dem Weg der rechtlichen Neujustierung der Wirtschafts- und Währungsunion mit dem Beschluss des Europäischen Rates vom 25. März $2011^{79}$ betreten worden. Er ist auf eine erste Primärrechtsänderung im Wege des durch den Vertrag von Lissabon neu geschaffenen vereinfachten Vertragsänderungsverfahrens ${ }^{80}$ gerichtet, mit dem die Union keine neue Zuständigkeit erhalten kann. Dies soll auch nicht ge-

74 Bundesverfassungsgericht 2BvR 987/10, 2BvR 1485/10, 2 BvR 1099/10, Tz. 130ff. (Beschränkung auf evidente Verletzungen; Respektierung des Einschätzungsspielraums namentlich im Blick auf das Eintrittsrisiko von Gewährleistungen).

75 Ebenda, Tz. 132.

76 Ebenda, Tz. 125 und 136 (Verbot eines Automatismus im Widerspruch zur Haushaltsautonomie des Bundestages).

77 Das Budgethilfen-Urteil enthält durchaus Einschränkungen in der Wahl künftiger Maßnahmen, die entweder nur durch den verfassungsändernden Gesetzgeber oder sogar nur durch eine neue deutsche Verfassung überwunden werden können. Vgl. Müller-Graff: L'arrêt de Karlsruhe, 2011, S. 5-14; zum politischen Problem des zweitgenannten Weges jüngst Georg Paul Hefty: Eine neue Verfassung?, in: Frankfurter Allgemeine Zeitung, 24.10.2011.

78 Vgl. dazu Steffen Kampeter: Wir müssen den Weg einer weiteren Integration gehen, in: Finanzplatz 6/2011, S. 4-8, hier S. 6-7.

79 Beschluss des Europäischen Rates vom 25. März 2011 zur Änderung des Artikels 136 des Vertrages über die Arbeitsweise der Europäischen Union hinsichtlich eines Stabilitätsmechanismus für die Mitgliedstaaten, deren Währung der Euro ist (2011/199/EU), in: Amtsblatt der EU, Nr. L 91 vom 6. April 2011, S. 1-2.

80 Art. 48 Abs. 6 EUV. 
schehen.$^{81}$ In dem nur für die Eurostaaten geltenden Art. 136 AEUV soll vielmehr ein dritter Absatz mit dem Text eingefügt werden: „Die Mitgliedstaaten, deren Währung der Euro ist, können einen Stabilitätsmechanismus einrichten, der aktiviert wird, wenn dies unabdingbar ist, um die Stabilität des Euro-Währungsgebietes insgesamt zu wahren. Die Gewährung aller erforderlichen Finanzhilfen im Rahmen des Mechanismus wird strengen Auflagen unterliegen.“ Dieser Beschluss des Europäischen Rates tritt gemäß Art. 48 Abs. 6 EUV „erst nach Zustimmung [aller] Mitgliedstaaten [der Union] im Einklang mit ihren jeweiligen verfassungsrechtlichen Vorschriften in Kraft." Bemerkenswert wird damit primärrechtlich ausdrücklich die Möglichkeit anerkannt, zwischen einer Teilmenge von Mitgliedstaaten der Union (den Eurostaaten) Budgethilfen außerhalb des Unionsrechts und dessen spezifischer Supranationalität zu gewähren, ohne dass damit aber schon entschieden wäre, ob der neue „Mechanismus“ intergouvernemental oder auf eine eigene, neben dem Unionsrecht stehende Weise auch supranational ausgestaltet wird.

\section{Der geplante Europäische Stabilitätsmechanismus}

Eine neue rechtliche Integrationsdimension wird mit dem geplanten ESM ins Auge gefasst, der parallel zur projektierten Vertragsänderung errichtet werden soll. Die Texteinigung über den „Vertrag zur Einrichtung des Europäischen Stabilitätsmechanismus“ (ESMV) wurde seitens der Finanzminister der Eurostaaten bereits am 20. Juni 2011 erzielt. ${ }^{82}$ Danach soll der ESM als eigenständige internationale Finanzinstitution der Eurostaaten ${ }^{83}$ mit einem genehmigten Stammkapital von 700 Milliarden Euro ${ }^{84}$ (mit Änderungsverfahren ${ }^{85}$ ) durch einen vom Unionsrecht unabhängigen Vertrag der Eurostaaten geschaffen werden. ${ }^{86}$

Zweck des ESM ist die Mobilisierung von Finanzmitteln, um ESM-Mitgliedern mit schwerwiegenden Finanzproblemen eine Finanzhilfe bereitzustellen, ${ }^{87}$ namentlich durch Gewährung eines verzinslichen Darlehens ${ }^{88}$ und ausnahmsweise durch Ankauf von Anleihen eines ESM-Mitglieds am Primärmarkt. ${ }^{89} \mathrm{Zu}$ diesem Zweck soll er berechtigt sein, Mittel aufzunehmen, ${ }^{90}$ namentlich durch Begebung von Finanzinstrumenten (Anleihenaufnahme ${ }^{91}$ ) oder Abschluss von Vereinbarungen mit ESM-Mitgliedern, Finanzinstituten oder sonstigen Dritten.

Rechtskategorial bemerkenswert ist daran zuallererst, dass das unionsrechtlich verankerte supranationale Projekt der Währungsunion ${ }^{92}$ durch eine außerunionsrechtliche völker-

81 Zutreffend Ulrich Häde: Rechtliche Aspekte der europäischen Schuldenkrise: Zwischen europäischer Kompetenzanmaßung und nationaler Kontrolle, in: Timm Beichelt/Nicolai von Ondarza/Günter Verheugen (Hrsg.): Die EU auf dem Weg zur Wirtschaftsregierung? Europäische Reaktionen auf die Finanz-, Wirtschafts- und Schuldenkrise, MES-Perspektiven 1/2011, S. 22-24.

82 Vertrag zur Einrichtung des Europäischen Stabilitätsmechanismus (ESM) zwischen dem Königreich Belgien, der Bundesrepublik Deutschland, der Republik Estland, Irland, der Hellenischen Republik, dem Königreich Spanien, der Französischen Republik, der Italienischen Republik, der Republik Zypern, dem Großherzogtum Luxemburg, der Republik Malta, dem Königreich der Niederlande, der Republik Österreich, der Portugiesischen Republik, der Republik Slowenien, der Slowakischen Republik, der Republik Finnland, T/ESM/de.

83 Art. 1 ESMV.

84 Art. 8 Abs. 1 ESMV.

85 Art. 10 ESMV.

86 Zum Schnittfeld zwischen ESM-Projekt und Grundgesetz Ulrich Hufeld: Zwischen Notrettung und Rütlischwur, in: integration 2/2011, S. 117-131.

87 Art. 3 ESMV.

88 Art. 14 ESMV.

89 Art. 15 ESMV.

90 Art. 3 ESMV.

91 Art. 17 ESMV.

92 Art. 3 Abs. 4 EUV, Artt. 119ff., 127ff. AEUV. 
vertragliche Vereinbarung gestützt werden soll. Die anläßlich der Tagung des Europäischen Rates am 9. Dezember 2011 von den Staats- und Regierungschefs des Euro-Währungsgebietes ins Auge gefaßte ,,verstärkte Architektur für die Wirtschafts- und Währungsunion“93 mit einem neuen fiskalpolitischen Pakt und einer engeren politischen Koordinierung und verstärkten Steuerung geht in dieselbe rechtliche Richtung. Konzeptionelle und primärrechtliche Bedenken der öffentlichen Diskussion gegen die Unvereinbarkeit des geplanten ESM mit dem derzeitigen Konzept des Primärrechts (,keine Schuldenunion“, „keine Transferunion“94) sollen flankierend durch die erwähnte mikroinvasive Vertragsergänzung ${ }^{95}$ beseitigt werden. Scheitert diese Vertragsänderung, stellt sich die Frage, ob die Einrichtung des ESM auch ohne sie unionsrechtskonform wäre. Dies hängt wiederum von der oben erörterten Auslegung des Art. 125 AEUV ab.

Rechtsorganisationell ist der ESM als eigenständige ,internationale Finanzinstitution“ mit eigener Rechtspersönlichkeit und eigenen Organen (Gouverneursrat, Direktorium, Geschäftsführender Direktor) mit Sitz in Luxemburg konzipiert. ${ }^{96}$ Aus dieser Formulierung und aus der Rechtsstatuszuweisung im Einzelnen ${ }^{97}$ sowie aus der Tatsache, dass die Auslegung des ESMV anders als diejenige des EFSF-Rahmenvertrags nicht einem nationalen Recht unterworfen und bei Anfechtung von Entscheidungen des Gouverneurrates des ESM der EuGH als Schiedsgericht berufen wird, ${ }^{98}$ ergibt sich der Charakter des ESM als einer eigenständigen völkerrechtlichen Organisation. Vorgesehen sind allerdings einige Verbindungen zur Union. Neben der unionsrechtlich auch hier legitimierten Anrufbarkeit des EuGH ${ }^{99}$ in Streitigkeiten zwischen ESM-Mitgliedern sowie zwischen ESM-Mitgliedern und dem ESM $^{100}$ wird die Überwachung „nach Abschluss des Programms“ der Durchführung durch die Kommission und den Rat der Union im Rahmen des wirtschaftsunionsrechtlichen Koordinierungsverfahrens zugewiesen. ${ }^{101}$ Beschlüsse des Gouverneursrates und des Direktoriums werden je nach Beschlussgegenstand im Einvernehmen, mit qualifizierter Mehrheit (80 Prozent der abgegebenen Stimmen) oder mit einfacher Mehrheit gefasst. ${ }^{102}$ Hierbei entsprechen die Stimmrechte eines jeden ESM-Mitglieds der Zahl der Anteile, die ihm am genehmigten Stammkapital des ESM zugeteilt werden; ${ }^{103}$ diese ergeben sich wiederum in Anlehnung an den EZB-Schlüssel (für Deutschland 27,1464 Prozent ${ }^{104}$ ). Aus der eigenen Rechtspersönlichkeit des ESM folgt, dass Gläubiger und Schuldner der Aktivitäten des ESM nicht die Mitgliedstaaten sind, sondern der ESM. In dieser Konstruktion wird Deutschland im schlimmsten Fall seine Einlage verlieren (circa 190 Milliarden Euro).

93 Europäischer Rat: Erklärung der Staats- und Regierungschefs des Eurowährungsgebiets, Brüssel, den 9. Dezember 2011, S. 2.

94 Zur Diskussion vgl. zum Beispiel Handelsblatt: Schäuble erteilt Euro-Transferunion scharfe Absage, 18.05.2011; Faz.net: „Weder der Weg zu Eurobonds noch zur Transferunion“, 21.09.2011; Guido Westerwelle, in: Deutscher Bundestag. Stenografischer Bericht 123. Sitzung, Berlin, Mittwoch, den 7. September 2011, Plenarprotokoll 17/123, S. 14443 B-14446 D, hier S. 14444 A.

95 Art. 136 Abs. 3 AEUV.

96 Art. 1 Abs. 1, Artt. 4ff., Art. 26 Abs. 1, Art. 27 Abs. 2 ESMV.

97 Art. 27 ESMV.

98 Art. 32 ESMV.

99 Jurisdiktion des EuGH zugänglich über Art. 273 AEUV (Schiedsvertrag).

100 Art. 32 Abs. 3 ESMV; siehe auch 12. Erwägungsgrund der Präambel des ESMV.

101 Vgl. 13. Erwägungsgrund der Präambel des ESMV unter Bezugnahme auf Artt. 121, 136 AEUV.

102 Art. 4 Abs. 2 bis 5 ESMV; speziell zum Gouverneursrat Art. 5 Abs. 6 und 7 ESMV, zum Direktorium Art. 6 Abs. 5 ESMV.

103 So Art. 4 Abs. 6 ESMV.

104 Vgl. Art. 11 Abs. 1 ESMV; Anhang I und II des ESMV. 


\section{Die Anleihenkäufe der Europäischen Zentralbank}

Schließlich sind die seit 2010 erfolgten Ankäufe von Anleihen von Problemstaaten durch die EZB Erwerbsvorgänge durch ein Organ der Union, ${ }^{105}$ das allerdings im Vergleich zu anderen Unionsorganen die Besonderheit eigener Rechtspersönlichkeit aufweist. ${ }^{106}$ Die Ankaufspraxis der EZB in der gegenwärtigen Staatsschuldenkrise seit 2010 enthält ein primärrechtliches Problem. Zwar ist der EZB durch Art. 123 AEUV nur der unmittelbare Erwerb staatlicher Schuldtitel untersagt (Erwerbsverbot am Primärmarkt), ${ }^{107}$ nicht aber auch der mittelbare Erwerb (Sekundärmarkt; Offenmarktpolitik). Da letzterer nach dem Normzweck des Art. 123 AEUV aber nur deshalb erlaubt sein kann, weil sich die Anleihen in einem derartigen Fall bereits durch den Ersterwerb eines Investors ,,am Markt bewährt“ haben, ${ }^{108}$ widerspricht der Zweiterwerb dann dem Sinn der Vorschrift und ist eine vertragswidrige Verbotsumgehung, wenn er Anleihen notleidender Eurostaaten betrifft, deren Aufkauf die EZB zuvor generell angekündigt und dadurch die Ersterwerber von vornherein von dem Risiko eines Ausfalls befreit hat. In einer derartigen Situation kann von einer Bewährung dieser Anleihen auf dem Primärmarkt überhaupt nicht die Rede sein. In Konsequenz derartiger Ankäufe wird allein die EZB Gläubiger, nicht aber werden es die Mitgliedstaaten. Verluste der EZB aus derartigen Geschäften werden allerdings politische Deckungsforderungen an die Eurostaaten auslösen. ${ }^{109} \mathrm{Im}$ Übrigen verstieße der derzeit insbesondere von anderen Währungsräumen und den Investoren geforderte Einsatz der EZB zur politikstützenden Geldmengenvermehrung gegen die Primäraufgabe des ESZB ${ }^{110}$ und ist als Einschränkung dieser Primärpflicht nicht ohne Vertragsänderung gemäß Art. 48 EUV zulässig.

Unionaler Sixpack in Gestalt der legislativen Entschließungen des Europäischen Parlaments vom 28. September 2011

Der sogenannte unionale Sixpack in Gestalt der legislativen Entschließungen des Europäischen Parlaments vom 28. September 2011 umfasst fünf Verordnungsvorschläge und einen Richtlinienvorschlag der Kommission. Sie beziehen sich anders als die bisher erörterten Maßnahmen nicht auf finanzielle Budgethilfen für bereits in Schwierigkeiten geratene Staaten, sondern zielen auf Präventivmaßnahmen für alle Mitgliedstaaten oder speziell für die Eurostaaten. Für alle Mitgliedstaaten geht es um die Stärkung der haushaltspolitischen Überwachung und der Überwachung und Koordinierung der Wirtschaftspolitiken, ${ }^{11}$ die Beschleunigung und Klärung des Verfahrens bei einem übermäßigen Defizit, ${ }^{112}$ die Vermei-

105 Die EZB hat Organqualität seit dem Vertrag von Lissabon. Vgl. Art. 13 EUV.

106 Art. 282 Abs. 3 AEUV.

107 Vgl. zu Zweck und Stellung der Norm zum Beispiel Ulrich Häde, in Christian Callies/Matthias Ruffert (Hrsg.): EUV/EG. Kommentar zu EU-Vertrag und EG-Vertrag, 3. Aufl., München 2007, Art. 101, Rdz. 1ff.; Ulrich Kempen, in: Rudolf Streinz: EUV/EGV. Kommentar, München 2003, Art. 101, Rdz. 1; Peter Part, in: Heinz Mayer (Hrsg.): Kommentar zu EU- und EG-Vertrag, Wien 2004, Art. 101 EGV, Rd.1ff.

108 Plastisch spricht Peter Part davon, der Staat müsse zuerst ,die Marktbewertung durchlaufen.“ Vgl. Part, in: Mayer: Kommentar zu EU- und EG-Vertrag, 2004, Art. 101 EGV, Rdz. 6.

109 Zum Schlüssel für die Zeichnung des Kapitals der EZB durch die nationalen Zentralbanken vgl. Art. 28, 29 des Protokolls (Nr. 4) über die Satzung des Europäischen Systems der Zentralbanken und der Europäischen Zentralbank, in: Amtsblatt der EU, Nr. C 83 vom 30. März 2010, S. 230-260.

110 Art. 127 AEUV.

111 Europäische Kommission: Vorschlag für eine Verordnung des Europäischen Parlaments und des Rates zur Änderung der Verordnung (EG) Nr. 1466/97 über den Ausbau der haushaltspolitischen Überwachung und der Überwachung und Koordinierung der Wirtschaftspolitiken, KOM (2010) 526.

112 Europäische Kommission: Vorschlag für eine Verordnung (EU) NR. .../... des Rates zur Änderung der Verordnung (EG) Nr. 1467/97 über die Beschleunigung und Klärung des Verfahrens bei einem übermäßigen Defizit, KOM (2010) 522. 
dung und Korrektur makroökonomischer Ungleichgewichte ${ }^{113}$ und die Fixierung der Anforderungen an die haushaltspolitischen Rahmen der Mitgliedstaaten. ${ }^{114}$ Zwei Verordnungsvorschläge betreffen speziell die Eurostaaten, nämlich die wirksame Durchsetzung der haushaltspolitischen Überwachung im Euroraum ${ }^{115}$ und die Durchsetzungsmaßnahmen zur Korrektur übermäßiger makroökonomischer Ungleichgewichte im Euroraum. ${ }^{116}$ Nicht jede der in diesem Maßnahmenpaket vorgesehenen Regeln dürfte jedoch von dem derzeitigen Zuständigkeitsspektrum der Union gedeckt, sondern nur mittels einer Vertragsänderung verwirklichbar sein. ${ }^{117}$

\section{Rechtspolitische Problemperspektiven}

Auf dem seit Mai 2010 in rechtliches Neuland eingeschlagenen Weg sind verschiedene rechtspolitische Problemperspektiven erkennbar. Dazu rechnet nicht zuletzt das Dauerproblem der aufgabenadäquaten Gestaltung der parlamentarischen Kontrolle bei neuen Integrationsschritten und/oder Integrationsmustern (in Deutschland der Parlamentsvorbehalt und die aus dem Demokratieprinzip folgende Haushaltsautonomie und Haushaltsverantwortung des Bundestages ${ }^{118}$ ). Dies soll nachfolgend aber nicht vertieft werden. Unter dem Gesichtspunkt der Integrationspolitik aufgegriffen werden vielmehr drei Problemperspektiven der Entwicklung des Rechts des europäischen Zusammenhalts: die sich verschärfende Alternative zwischen Unionsrecht und Euroraum-Sonderrecht, die gleichermaßen akzentuierte Alternative zwischen intergouvernementalem Recht und supranationalem Recht und die mitlaufende Alternative zwischen judikativer Kontrolle sowie rechtlicher (und darin auch demokratischer) Bindung und politischem Freilauf.

\section{Alternative zwischen Unionsrecht und Euroraum-Recht}

Wie aufgezeigt soll die auf den Weg gebrachte Ergänzung des Art. 136 AEUV um einen dritten Absatz den Eurostaaten für einen Stabilitätsmechanismus den Weg aus dem Unionsrecht heraus primärrechtlich ausdrücklich absichern.

Primärrechtliche Erforderlichkeit und Zulässigkeit: Fraglich ist freilich, ob oder inwieweit einerseits die Budgethilfenpolitik zwischen den Eurostaaten einer derartigen Änderung primärrechtlich überhaupt bedarf und andererseits der Mechanismus durch die Vertragsänderung unionsrechtliche Verpflichtungen der Eurostaaten aufhebt. Die Vertragsänderung ist dann nicht nötig, wenn, wie hier vertreten, das derzeitige Primärrecht freiwillige Budgethilfen nicht rundweg untersagt, sondern nur die in Art. 125 AEUV genannten Hilfsmethoden. Immerhin schafft die Vertragsergänzung aber dessen ungeachtet die primärrechtlich verankerte ausdrückliche Billigung aller Mitgliedstaaten der Union für einen freiwilligen Beistand zwischen den Eurostaaten. Sie beinhaltet damit aber auch einen Konzeptionswechsel von der Währungsunion ohne Beistand zu einer Währungsunion mit Beistandsmöglichkeit.

113 Europäische Kommission: Vorschlag für eine Verordnung des Europäischen Parlaments und des Rates über die Vermeidung und Korrektur makroökonomischer Ungleichgewichte, KOM (2010) 527.

114 Europäische Kommission: Vorschlag für eine Richtlinie des Rates über die Anforderungen an die haushaltspolitischen Rahmen der Mitgliedstaaten, KOM (2010) 523.

115 Europäische Kommission: Vorschlag für eine Verordnung des Europäischen Parlaments und des Rates über die wirksame Durchsetzung der haushaltspolitischen Überwachung im Euroraum, KOM (2010) 524.

116 Europäische Kommission: Vorschlag für eine Verordnung des Europäischen Parlaments und des Rates über Durchsetzungsmaßnahmen zur Korrektur übermäßiger makroökonomischer Ungleichgewichte im Euroraum, KOM (2010) 525.

117 Siehe dazu noch unten und ebenso Häde: Rechtliche Aspekte der europäischen Schuldenkrise, 2011, S. 23.

118 Vgl. dazu im Einzelnen im Blick auf die Budgethilfen-Gesetze vom Mai 2010 das Bundesverfassungsgericht 2BvR 987/10, 2BvR 1485/10, 2 BvR 1099/10, Tz. 120ff. 
Nicht nachgegangen werden kann hier der Frage, ob den Eurostaaten auch eine Verstärkte Zusammenarbeit im Vertragssinne ${ }^{119}$ möglich wäre.

Eine Entlastung von primärrechtlichen Pflichten durch die eingeleitete Vertragsänderung ist freilich nur in dem Maße möglich, in dem die angestrebte Vorschrift dies als Spezialregelung vorsieht (, lex specialis '-Gedanke). Jedenfalls eine Einschränkung des Primärrechts der wettbewerbsverfassten Marktwirtschaft ist damit nicht verbunden. Kommt es etwa durch das Agieren des von einer Teilmenge der Mitgliedstaaten getragenen ESM zu wettbewerbsverfälschenden Hilfsmaßnahmen an einzelne Banken, sind diese Maßnahmen grundsätzlich als staatlich zurechenbare Beihilfen dem Beihilfenaufsichtsrecht der Union (Artt. 107ff. AEUV) unterworfen.

Integrationsförderung durch Differenzierung: Das mit dem eingeleiteten Vertragsänderungsverfahren thematisierte und mit dem ESMV angestrebte Euroraum-Sonderrecht verstärkt die Differenzierung der Rechtsbindung zwischen den Eurostaaten (Euroraum-Recht) und den Mitgliedstaaten, die nicht dem Euroraum angehören. Differenzierungen im Integrationsstatus sind ambivalent. Sie können einerseits den homogenen Zusammenhalt beeinträchtigen, ihn andererseits aber als vorausgehende Teilintegration fördern. ${ }^{120}$ Inwieweit die nach bisherigen Erfahrungen erkennbare integrationsfördernde Binnenmarktnähe eines Gegenstands differenzierter Integration ${ }^{121}$ (wie namentlich bei den Schengen-Abkommen) auch im Fall der Budgethilfen im Euroraum mit hinreichender Wirkkraft vorhanden ist, ist eine schwierige prognostische Frage. Eine derartige Wirkkraft ist wegen der funktionalen Sinnverknüpfung zwischen Binnenmarkt und Währungsunion (Beseitigung großflächiger Wettbewerbsverzerrungen infolge von Ab- und Aufwertungen einzelstaatlicher Währungen $^{122}$ ) und auch wegen der Sogkraft großer Währungsräume nicht ausgeschlossen, andererseits aber vor allem von der Bereitschaft und der Fähigkeit eines Staates zur Mitgliedschaft in der Währungsunion abhängig. ${ }^{123}$

Differenzierung als Folge des Konzepts der Wirtschafts- und Währungsunion: Unabhängig von diesem unklaren Aspekt der mittel- oder langfristigen Integrationsförderung in der Union befestigt die eingeleitete Vertragsänderung lediglich eine Differenzierung in derjenigen Rechtsbindung der Unionsstaaten, die im Primärrecht durch die Vorschriften zur Wirtschafts- und Währungsunion schon jetzt angelegt ist. Dies gilt auch wegen der bereits bestehenden, freilich begrenzten Ermächtigung des Rates zum Erlass von Maßnahmen speziell für die Eurostaaten sowohl im Bereich der Koordinierung und Überwachung ihrer Haushaltsdisziplin als auch der Ausarbeitung der Grundzüge der Wirtschaftspolitik. ${ }^{124}$ Der ESM hat zudem den unabweisbaren sinnfälligen Vorteil, dass nur die in ihrer gemeinsamen Währung unmittelbar betroffenen und belasteten Staaten mitwirken. Die konkrete Ausgestaltung der Wirtschafts- und Währungsunion profiliert sich damit aus Sachgründen zunehmend als eine zwar nicht rechtstechnisch, wohl aber vom Primärrecht nach eigenen Regeln (insbeson-

$119 \mathrm{Zu}$ den Voraussetzungen vgl. Art. 20 EUV. Insoweit fällt auf, dass die freiwillige Budgethilfe nicht nur keine ausschließliche Kompetenz der Union, sondern außerhalb des Art. 122 AEUV überhaupt keine Zuständigkeit der Union und deren Organe einschließlich der EZB ist. Art. 352 AEUV, falls überhaupt anwendbar, ist eine jenseits seiner abstrakten Formulierung sachgegenständlich unspezifische Kompetenz.

120 Vgl. dazu Peter-Christian Müller-Graff: ,Differenzierte Integration“: Konzept mit sprengender oder unitarisierender Kraft für die Europäische Union?, in: integration 2/2007, S. 129-139.

121 Ebenda.

122 Vgl. Peter-Christian Müller-Graff: Die Kompetenzen in der Europäischen Union, in: Werner Weidenfeld/ Wolfgang Wessels (Hrsg.): Europa-Handbuch, Band 1, 3. Aufl., Gütersloh 2004, S. 141-165, hier S. 154.

123 Hinsichtlich der Bereitschaft gilt dies bekanntlich insbesondere für das Vereinigte Königreich, hinsichtlich der Fähigkeit insbesondere für Griechenland. Vgl. dazu jüngst Rolf Caesar: Warum Griechenland den Euro aufgeben muss, in: ZeitOnline, 14.11.2011.

124 Vgl. Art. 136 Abs. 1 AEUV. 
dere Aufnahmevoraussetzungen und Mitwirkungsverpflichtung) angelegte Form der verstärkten Zusammenarbeit einer Teilmenge der Unionsstaaten.

Die rechtliche Sonderentwicklung des Pfades der Euroraum-Budgethilfen wird dadurch etwas gedämpft, dass erstens ein Zusammenspiel zwischen supranationaler unionsrechtlicher Pflicht und Euroraum-Sonderrecht schon von der projektierten Vertragsänderung über die Verknüpfung von Finanzhilfen mit strengen Auflagen vorgesehen ist. Zweitens lässt sich der vorgesehenen Vertragsänderung, soweit sie keine Sonderregelung enthält, keine Entpflichtung der Eurostaaten vom Unionsrecht entnehmen, sodass auch für diese unverändert namentlich die binnenmarktlichen Grundfreiheiten und Wettbewerbsregeln einschließlich der Beihilfeaufsichtsregeln sowie die Verpflichtung auf eine offene Marktwirtschaft mit freiem Wettbewerb gelten. Hinzu kommt, dass im Rahmen des ESMV, wie gezeigt, eine punktuelle Verbindung zu Unionsorganen vorgesehen oder möglich ist. ${ }^{125}$

\section{Alternative zwischen supranationalem und intergouvernementalem Recht}

Mit den einzelnen, seit Mai 2010 genommenen Schritten hat für die Entwicklung des Integrationsrechts zugleich die Alternative zwischen supranationalem und intergouvernementalem Recht an Aktualität gewonnen.

Intergouvernementale Mechanismen im Interesse der Supranationalität: Bemerkenswert an der Entwicklung seit Mai 2010 ist, dass zu dem Zweck, die supranational konzipierte Währungsunion zu stabilisieren, in nicht geringem Umfang intergouvernementale Instrumente eingesetzt werden oder werden sollen: so die Griechenlandhilfe, die EFSF, die erweiterte EFSF und der ESM sowie die von den Staats- und Regierungschefs des Euro-Währungsgebietes mit ihrer Erklärung vom 9. Dezember 2011 angestrebte ,verstärkte Architektur"126 für die Wirtschafts- und Währungsunion. Die auf die Zustimmungsbahn gebrachte mikroinvasive Vertragsänderung ${ }^{127}$ schließt diesen Weg jedenfalls nicht aus, erzwingt ihn aber auch nicht. In dem mit dem ESM eingeschlagenen Weg ließe sich jedenfalls bei erster Betrachtung für die Eurostaaten ein Paradigmenwechsel von der Supranationalität in die Intergouvernementalität sehen. Indes griffe dies zu kurz. Denn Budgethilfen (,Finanzhilfen'), auch wenn sie auf Eurostaaten beschränkt bleiben, betreffen die staatliche Haushaltspolitik und damit, in der Systematik des Primärrechts gedacht, zuallererst die im Ansatz $^{128}$ intergouvernemental angelegte Wirtschaftsunion sowie die Finanzierung von Staatshaushalten über den Kapitalmarkt. Im Licht der im Primärrecht der Wirtschaftsunion zum Ausdruck kommenden Souveränitätsschonung der Mitgliedstaaten sind die intergouvernementalen Hilfsschritte der Eurostaaten primärrechtlich jedenfalls nicht systemfremd. Fraglich ist allerdings, ob sie für eine dauerhafte Stabilität der Währungsunion ausreichen.

Rechtskategoriale Alternative oder Ergänzung? Damit geht es in Konsequenz um die Frage, ob es vorzugswürdig ist, die Regeln für die Koordinierung der Wirtschaftspolitik (,Wirtschaftsregierung') und für Budgethilfen in der Währungsunion intergouvernemental oder supranational auszugestalten. Konzipierbar ist beides, streitig aber auch. An Forderungen nach mehr Supranationalität fehlt es nicht, ${ }^{129}$ an Kritik an solchen Vorschlägen aller-

125 Vgl. oben zum ESM.

126 Europäischer Rat: Erklärung der Staats- und Regierungschefs des Eurowährungsgebiets, 9. Dezember 2011, S. 2.

127 Vgl. anvisierter Art. 136 Abs. 3 AEUV.

128 Siehe oben im Text.

129 Vgl. zum Beispiel jüngst Kampeter: Wir müssen den Weg einer weiteren Integration gehen, 2011: „Es geht um ein echtes Mehr an europäischer Integration, also um eine engere, verstärkte und intensivierte Steuerung der Finanz- und Wirtschaftspolitik innerhalb der Eurozone“. 
dings auch nicht. ${ }^{130}$ Hierbei empfiehlt sich, zunächst die zu lösenden Problemkreise zu substantiieren und abzugrenzen.

Soweit es um die Festlegung der Konditionen von Auszahlung, Verwendung und Rückzahlung von Budgethilfen geht, böte deren supranationale Fixierung - abstrakt rechtskategorial gedacht - das Potenzial unmittelbar anwendbaren Rechts und - innerhalb des Unionsrechts - bei Nichteinhaltung der Konditionen die Möglichkeit der Feststellung als Vertragsverletzung durch den EuGH und gegebenenfalls eine daraus folgende unionsrechtliche Sanktionierung. Soweit es im Kern um die Kontrolle der Haushalts- und Wirtschaftspolitik der Eurostaaten geht, gilt dies - modellmäßig gedacht - grundsätzlich gleichermaßen. Da damit aber essenzielle Bereiche staatlicher Selbstbestimmung und Demokratie betroffen sind, speziell in Deutschland nach der Rechtsprechung des Bundesverfassungsgerichts ein auch dem verfassungsändernden Gesetzgeber unverfügbarer Teil souveräner Staatlichkeit, ${ }^{131}$ wirft eine supranationale Ausgestaltung (mit Haushaltskommissar und Durchgriffsrechten auf die staatliche Budgetgestaltung) sowohl normative Probleme als auch das bereits erkennbare Problem der Entzündung kontraproduktiver Gegenkräfte auf. Der Effekt ,von außen` kommender oder als, von außen` kommend empfundener rechtlich ,harter' Maßnahmen dürfte vermutlich begrenzt sein. Ihre Möglichkeit sollte als präventives Druckmittel nicht ausgeschlossen sein, doch wird die Hauptlast auf Maßnahmen liegen, die deren überzeugungsgetragene freiwillige Befolgung fördern.

Daraus lässt sich folgern, dass die Zuspitzung der Perspektive auf die Alternative zwischen supranationalem oder intergouvernementalem Recht in der Frage der Haushaltsdisziplin zu eng geführt ist. Sie wird der Besonderheit Europas nicht gerecht. Zur Diskussion steht nicht ein ,entweder-oder', sondern ein kombinatives Konzept aus mehreren Elementen: der grundsätzlichen mitgliedstaatlichen Eigenverantwortung, der präventiven Koordinierung, ${ }^{132}$ der Nutzung privatrechtlicher Gestaltungsmittel am Kapitalmarkt, der Verfügbarkeit supranationaler Instrumente und der Möglichkeit ausnahmsweiser Budgethilfe. Auch hierin wird Europas Besonderheit erkennbar, das eben kein Staat wie China oder die USA ist und auch nicht sein will, sondern die historische Innovation einer neuen und modernen transnationalen Ordnung wagt und diese in neuen Herausforderungen passfähig zu ihrer Eigenheit zu entwickeln hat. Die seit Mai 2010 ergriffenen Maßnahmen zeigen, dass die Praxis der Krisenbewältigung und Krisenvorsorge in ihrer tastenden Suche nach einer neuen Justierung von supranationalen und intergouvernementalen Elementen in der Wirtschaftsunion mit besonderem Blick auf die Eurostaaten diesen Pfad bereits eingeschlagen hat. Als sinnfällig für künftige Krisenvermeidung wird hierbei die Beibehaltung der grundsätzlichen wirtschafts- und haushaltspolitischen Verantwortungsstruktur der Mitgliedstaaten in der Wirtschaftsunion bei gleichzeitiger Verstärkung präventiver Instrumente und wechselseitiger Koordination jedenfalls im spezifisch verdichteten Euroraum erkennbar, zu denen neben

130 Vgl. zum Beispiel jüngst Hermann Lübbe: Vereinigte Staaten von Europa?, in: Frankfurter Allgemeine Zeitung, 15.10.2011.

131 So das Lissabon-Urteil des Bundesverfassungsgerichts, das die Budgethoheit zum Kern der souveränen Staatlichkeit im Sinne des Art. 79 Abs. 3 Grundgesetz rechnet: „Die Entscheidung über Einnahmen und Ausgaben der öffentlichen Hand ist grundlegender Teil der demokratischen Selbstgestaltungsfähigkeit im Verfassungsstaat.“ Vgl. BVerfGE 123, 267, 359; siehe auch im Budgethilfenurteil Bundesverfassungsgericht 2BvR 987/ 10, 2BvR 1485/10, 2 BvR 1099/10, Tz. 122.

132 Vgl. dazu jüngst Lüder Gerken/Bert Van Roosebeke/Jan S.Voßwinkel: Anforderungen an die Sanierung der Euro-Staaten. Schuldenbremse plus Nebenbedingungen, Centrum für Europäische Politik: CEP-Studie im Auftrag der Initiative Neue Soziale Marktwirtschaft, 19.09.2011; siehe auch Guy Verhofstadt: How can we save the Euro?, Gütersloh 2010. 
den Überwachungsverfahren auch das marktflexible Privatrecht mit der Konditionalisierung von Staatsanleihen beitragen kann.

Erfordernisse der Änderung des AEUV richten sich nach dem Grad der gewollten supranationalen Kontrolle innerhalb der Union. ${ }^{133}$ Inwieweit ohne Vertragsänderung die Regelungen im Sixpack von der jeweils herangezogenen Ermächtigungsgrundlage ${ }^{134}$ im Einzelnen getragen beziehungsweise nicht getragen werden, ${ }^{135}$ kann hier nicht vertieft werden. Zweifel bestehen jedenfalls hinsichtlich der angestrebten sekundärrechtlichen Stärkung der Kommission gegenüber dem Rat im Vergleich zu dem zwischen den Mitgliedstaaten primärrechtlich festgelegten Entscheidungsverfahren. Dies gilt namentlich für das Muster der Fiktion der Annahme einer von der Kommission empfohlenen Entscheidung, wenn sie der Rat nicht innerhalb einer bestimmten Frist ablehnt. ${ }^{136}$

Vorliegend interessiert jedoch die andere Frage, ob in der normativen Ausgestaltung oder Perspektive des ESMV Elemente enthalten sind, die zwar außerhalb des Unionsrechts siedeln, aber in ihrer Tendenz auf eine Steuerung einzelstaatlicher Budgetpolitik hinauslaufen. Sie ist im Einzelnen noch nicht ausgelotet und fordert auch eine Schärfung des rechtlichen Begriffs der Supranationalität, auch im Hinblick auf die verfassungsrechtlichen Zustimmungserfordernisse in Deutschland. Es ist gut denkbar, dass bei genauerer Analyse die Scharfkantigkeit der ohnehin groben Unterscheidung zwischen Supranationalität und Intergouvernementalität in der Wirtschafts- und Währungsunion der Eurostaaten verschwimmt oder sich in neuen Elementen zeigt.

\section{Alternative zwischen judikativer Kontrolle und politischem Freiraum}

Eine dritte Problemperspektive in der rechtlichen Dimension des seit Mai 2010 eingeschlagenen Weges der Budgethilfen betrifft die judikative und damit rechtliche Kontrolle und Kontrollierbarkeit im Verhältnis zum rechtlich unkontrollierten politischen Freiraum. Sie ist mit den beiden ersten Problemperspektiven verknüpft, führt aber darüber hinaus.

Unionsrecht und Jurisdiktion: Die Frage nach judikativer Kontrolle ist mit der Alternative zwischen Unionsrecht und Euroraum-Sonderrecht insoweit verknüpft, als die Wahl unionsrechtlicher Mittel grundsätzlich deren Überprüfbarkeit durch den EuGH ins Spiel bringt. Zwar können nach derzeitigem Primärrecht, wie aufgezeigt, Verstöße gegen die mitgliedstaatliche Verpflichtung, ein übermäßiges öffentliches Defizit zu vermeiden, ${ }^{137}$ ebenso wie Verhaltensweisen bei der Durchführung im Rahmen der ersten Etappen des derzeitigen Haushaltsüberwachungsverfahrens ${ }^{138}$ nicht zum Gegenstand eines Vertragsverletzungsver-

133 Vgl. Müller-Graff: Die Europäische Wirtschafts- und Währungsunion, 2011, S. 885-900.

134 Artt. 121, 126, 136 AEUV.

135 Häde hält dies für „sehr zweifelhaft“ und Art. 136 Abs. 1 AEUV für zusätzliche und vorgezogene Sanktionen und für ein anderes als das bisher festgelegte Abstimmungsverfahren für nicht tragfähig. Vgl. Häde: Rechtliche Aspekte der europäischen Schuldenkrise, 2011, S. 2; siehe auch Ulrich Häde: Art. 136 AEUV - eine neue Generalklausel für die Wirtschafts- und Währungsunion?, in: Juristenzeitung 7/2011, S. 333-340.

136 So zum Beispiel Art. 6 Abs. 2 und Art. 10 Abs. 2 (Feststellung im Rahmen der multilateralen Überwachung nach Art. 121 AEUV, dass keine wirksamen Maßnahmen von einem Mitgliedstaat getroffen wurden) in der Legislativen Entschließung des Europäischen Parlaments vom 28. September 2011 zu dem Vorschlag für eine Verordnung des Europäischen Parlaments und des Rates zur Änderung der Verordnung (EG) Nr. 1466/97 über den Ausbau der haushaltspolitischen Überwachung und der Überwachung und Koordinierung der Wirtschaftspolitiken, P7_TA-PROV(2011)0421; Art. 10 Abs. 4 (Erklärung der Nichteinhaltung der Empfehlung) in der Legislativen Entschließung des Europäischen Parlaments vom 28. September 2011 zu dem Vorschlag für eine Verordnung des Europäischen Parlaments und des Rates über die Vermeidung und Korrektur makroökonomischer Ungleichgewichte, P7_TA-PROV(2011)0424.

137 Art. 126 Abs. 1 AEUV.

138 Art. 126 Abs. 2 bis 9 AEUV. 
fahrens vor dem EuGH gemacht werden. ${ }^{139}$ Aber zum einen ist dies durch eine Vertragsänderung korrigierbar. Und zum anderen sind bereits jetzt Maßnahmen der Union im Haushaltsüberwachungsverfahren dem Nichtigkeits-, Vorlage- oder Inzidentkontrollverfahren vor dem EuGH in deren jeweiligem Anwendungsbereich nicht entzogen. ${ }^{140}$ Dies gilt auch für den verordnungsgestützten EFSM ebenso wie für Maßnahmen der EZB. Allerdings ist die judikative Kontrolle sinnfälligerweise auf Fragen der Rechtmäßigkeit und Auslegung begrenzt. ${ }^{141}$ Dazu zählen neben der Frage der Kompetenz und Pflichtenbindung der Organe (zum Beispiel das Verbot des unmittelbaren Erwerbs von Schuldtiteln durch die EZB) auch Fragen der Eignung, Erforderlichkeit und Verhältnismäßigkeit von deren Maßnahmen. Nicht hingegen ist es Aufgabe speziell des EuGH und allgemein der Judikative, über die politische Zweckmäßigkeit und Risikoeinschätzung zu befinden (sofern diese nicht offenkundig fehlerhaft ist). Mithin wird der EuGH gut beraten sein, im System der Gewaltenteilung ebenso wenig wie das insoweit schon solcherart positionierte Bundesverfassungsgericht ${ }^{142}$ die Verantwortung für politische Risikoeinschätzungen zu übernehmen.

Intergouvernementalität und Jurisdiktion: Die Frage nach der judikativen und damit rechtlichen Kontrolle ist mit der Alternative zwischen supranationaler oder intergouvernementaler Ausgestaltung zwar nicht notwendig, aber doch tendenziell verknüpft. Zwar sind intergouvernementale oder klassisch völkervertragliche Vereinbarungen regelmäßig nicht mit der Einrichtung einer obligatorischen judikativen Streitschlichtung verbunden, wie es beispielsweise das insoweit nicht zu Ende gedachte Freizügigkeitsabkommen zwischen der Union und der Schweiz in all seiner kleinteiligen Problematik derzeit erleben lässt. ${ }^{143}$ Sie ist aber doch nicht ausgeschlossen. Dies belegt die seinerzeit vereinbarte Jurisdiktion des EuGH für das frühere Gerichtsstands- und Vollstreckungsübereinkommen in Zivil- und Handelssachen ${ }^{144}$ ebenso wie die geplante Einbeziehung des EuGH als Schiedsgericht in den ESM. In jedem Fall entspricht es dem elementaren rechtsstaatlichen Schutzgebot, der Verleihung von Hoheitsrechten eine obligatorische judikative Kontrolle deren Ausübung auf Antrag beizuordnen. Dies war der Ursprungsgedanke für die Einrichtung des EuGH als judikativer Kontrollinstanz von Maßnahmen der Hohen Behörde der Montanunion. Sollte sich der ESM als eine Organisation mit rechtsschutzbedürftigen Maßnahmen weiter entwickeln, müsste dies auch für ihn gelten und ebenso für neue Konstruktionen in Umsetzung der Erklärung der Staats- und Regierungschefs des Euro-Währungsgebietes vom 9. Dezember 2011. Allerdings wären im Falle von Hoheitsrechten auch insoweit die aus der Gewaltenteilung folgenden Grenzen judikativer Kontrolle zu präzisieren. Der Weg in transnational rechtliches Neuland ist daher zum rechtsstaatlichen Erfordernis des Rechtsschutzes kompatibel auszugestalten und daher insbesondere bei Schaffung von Hoheitsrechten grundsätzlich mit der Möglichkeit judikativer Überprüfbarkeit zu flankieren.

\section{Zusammenfassung}

Aus alledem ergibt sich, dass das seit Mai 2010 mit den Budgethilfen betretene Terrain nicht nur, aber auch rechtliches Neuland umfasst. Die bisherigen Schritte und die derzeit er-

139 So ausdrücklich Art. 126 Abs. 10 AEUV.

140 Siehe dazu schon oben EuGH, Rs. C-27/04 (Kommission/Rat), Slg. 2004, I-6649.

141 Vgl. namentlich Art. 263 Abs. 1 AEUV: „Der Gerichtshof der Europäischen Union überwacht die RechtmäBigkeit $[\ldots]$...

142 Bundesverfassungsgericht 2BvR 987/10, 2BvR 1485/10, 2 BvR 1099/10, Tz.130ff.

143 Auslegung der Dienstleistungsfreiheit des Freizügigkeitsabkommen im Hinblick auf die Zulässigkeit oder Unzulässigkeit von Kautionspflichten einzelner Kantone für die Erbringung von Baudienstleistungen.

144 BGB1. 1972 II, S. 773. 
kennbaren rechtspolitischen Perspektiven bewegen sich daher im zukunftsoffenen Potenzial von Risiken und Chancen differenzierter Integration für den Zusammenhalt der Europäischen Union. Die Tüchtigkeit der Realwirtschaft (und der darin liegenden Tugenden) sollte hierbei nicht von der uniformierenden Logik einer ungezügelten Finanzwirtschaft (und ihrem andersartig gespeisten Lebensmuster) oder einer unreflektierten Machtvision beschädigt und die Wurzeln der staatlichen Selbstverantwortung sollten im Rahmen einer Fiskalunion nicht geschwächt werden. Vielmehr gilt es, das vernünftige Maß zwischen Ambitionen, Eigenständigkeit und Zusammenwirken in der europäischen Wirtschafts- und Währungsunion sinnfällig zu justieren.

\section{Differenzierte Integration}

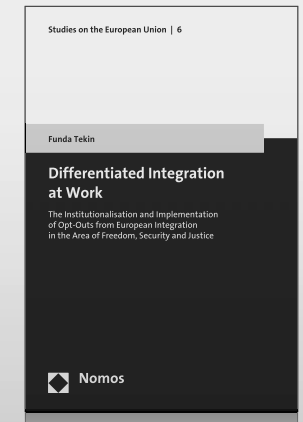

A nowor

Weitere Informationen: www.nomos-shop.de/14323

\section{Differentiated Integration}

\section{at Work}

The Institutionalisation and

Implementation of Opt-Outs from

European Integration in the Area of

Freedom, Security and Justice

Von Funda Tekin

2012, 330 S., brosch., 54,-€

ISBN 978-3-8329-7167-0

(Studies on the European Union, Bd. 6)

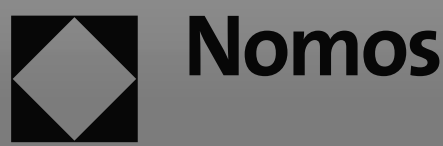

